\title{
Ecophysiological Features of Toxigenic Fungi Prevalent in Different Biotopes of Azerbaijan
}

\author{
Konul F. Bakshaliyeva ${ }^{1 *(\mathbb{D})}$, Nizami R. Namazov ${ }^{2, *} \mathbb{D}$, Sabia M. Jabrailzade ${ }^{3 \mathbb{D}}$, \\ Anahanum A. Yusifova ${ }^{3}$ (D), Afak L. Rzaeva ${ }^{4}$ (D) \\ 1 Institute of Microbiology of the Azerbaijan National Academy of Sciences, Baku, Azerbaijan \\ 2 Sumgait State University, Sumgait, Azerbaijan \\ 3 Azerbaijan State Pedagogical University, Baku, Azerbaijan \\ 4 Institute of Soil Science and Agrochemistry of the Azerbaijan National Academy of Sciences, Baku, Azerbaijan \\ * Correspondence: bahshaliyeva.imanas@ro.ru;
}

Received: 30.04.2020; Revised: 21.05.2020; Accepted: 23.05.2020; Published: 27.05.2020

\begin{abstract}
Our research into the ecophysiological features of phytotoxigenic fungi prevalent in different biotopes of Azerbaijan and representing soil-, plant- and water-derived micromycetes biotas are aiming at the determination of the ranges of environmental factors, which favor the fungal prevalence and phytotoxicity. We identified $\sim 130$ fungal species (representing the microbiotas of $\sim 2500$ samples), out of which 76 species were previously reported as phytotoxigenic. Of these phytotoxigenic fungi, 19 species showed strong $(>50 \%), 32$ species, intermediate $(10-50 \%)$, and 25 species, weak $(<10 \%)$ toxicity. The study of abiotic factors contributing to the fungal persistence reveals that, with regards to soil moisture preferences, only $9.5 \%$ of phytotoxigenic fungi belong to the hydrophiles, while $55.3 \%$ and $35.2 \%$ represent the xerophiles and the mesophiles, respectively. According to their thermal preferences, the studied fungi are divided into $89.9 \%$ of mesophiles and $10.1 \%$ of thermotolerant

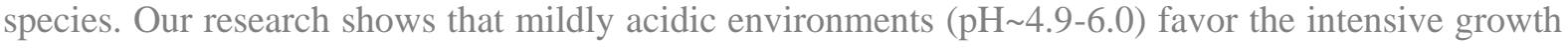
of most phytotoxigenic fungi. However, some alkaline-tolerant species such as Aspergillus fumigatus, Lichtheimia corymbifera and Mucor hiemalis are able to persist at $\mathrm{pH}$. Zygomycetes (Mucor hiemalis, Lichtheimia corymbifera and Rhizomucor miehei) are shown to have microaerophilic features, as far as the fungal oxygen requirements are concerned.
\end{abstract}

Keywords: mycobiota; phytotoxigenic species; temperature; soil moisture; acidity; light.

(C) 2020 by the authors. This article is an open-access article distributed under the terms and conditions of the Creative Commons Attribution (CC BY) license (https://creativecommons.org/licenses/by/4.0/).

\section{Introduction}

Fungi are the heterotrophic organisms, which occupy, virtually, any location rich in organic matter, and an incredibly wide range of fungal habitats differing in physicochemical conditions. This makes the study of the relationship between these parameters and the fungal features an important task [1,2].

Fungi exchange energy and chemical compounds with the local environment the exchange rate depending on abiotic and biotic environmental factors.

These include humidity, temperature, $\mathrm{pH}$, oxygen availability, illumination, etc. [3, 4]. Each of these factors has a specific contribution, and they act in a combined manner [5], while the variation of one factor results in the variation of the others. The combined effect of these factors on fungal traits remains underinvestigated in the current literature and, thus, requires 
more attention. In addition, the combined effect needs to be analyzed individually for each particular fungal biotope under study.

We, thus, aim to study the ecophysiological characteristics of fungi prevalent in different areas of Azerbaijan. We focus on a particular group, the phytotoxigenic fungi since toxigenicity is a form of expression of ecotropic specialization of fungi and not their immanent feature.

The fungi, which exert their toxigenic effects on the other species, have recently become the focus of current research. Toxigenic fungi represent a wide and non-uniform group of species, which differ from each other in their morphological features, nutrition, reproduction cycle, the range of habitats, as well as in their toxic effect on the other species [6-7]. The number of fungal species known to be able to produce toxic substances (mycotoxins) is increased annually. Besides, the toxigenicity of fungal species can vary greatly, and the same species can either produce one or several toxins or, conversely, no toxins at all [8]. However, the information on the relationship between the traits of phytotoxigenic fungi and the environmental factors is insufficient. It is important to establish the ecophysiological limits within which the phytotoxigenic fungi can persist in the territories of a certain areal.

Azerbaijan has a small territory, which, however, represents nine (out of eleven) types of climate, and includes two types of terrain (highlands and lowlands) with a wide number of biotopes with rich and rare flora [9]. Thus, the territory of Azerbaijan offers a great advantage for various aspects of mycological studies, including the relationship between the fungal phytotoxigenicity and environmental factors, which is the objective of our research.

\section{Materials and Methods}

\subsection{Sample collection.}

The samples of soil, water, and plants for fungal isolation were collected in the districts of Azerbaijan (Aran, Absheron, Ganja-Gazakh, Sheki-Zagatala, Lankaran-Astara, GubaKhachmaz, Mountain Shirvan and other economic regions of Azerbaijan) differing from each other in their area, terrain, type of farming, climate, soil type, and flora, as well as the level of technogenic influence on the water sources. Soil and plant samples represented the main types of soils in the areas and the prevalent wild-growing and cultivated medicinal herbs. Water samples from Absheron and Sheki-Zagatala areas lying in the Azerbaijan sector of the Greater Caucasus were collected from different water sources (lakes, rivers, and thermal springs). Samples were collected according to the established procedures [10-11] published by us and others [2, 12-13].

\subsection{Fungal isolation.}

Isolation of fungi from soil and water samples was performed by preparing a $10 \%(\mathrm{w} / \mathrm{v}$, for soil samples, and v/v, for water samples) water suspension, which was further diluted 10-, $100-$, and 500-fold. Water samples were merely diluted by water. The growth medium was inoculated by the dilutions and incubated at $28^{\circ} \mathrm{C}$ for 3-7 days.

Plant samples were washed with tap water, and affected parts were used for further processing. The surface of the sample was disinfected by $0.5 \% \mathrm{HgCl}_{2}$, and the sample was 3 times rinsed in sterile water to completely remove the disinfectant. The sample was then cut in 1-2 mm thick pieces by a sterile scalpel, and 3-5 pieces were transferred to agar Petri dishes. 
These cultures were incubated at $20^{\circ} \mathrm{C}$ due to the specific temperature requirements of some phytotoxic species and were checked on a daily basis for fungal growth.

In all cases, the fungal samples were stored, and the pure cultures were established using the standard growth media (wort agar, agarized Czapek medium, rice, or potato agar) [13].

\subsection{Identification of fungi.}

The fungal species of the established pure cultures were identified using the determinant guidebooks based on morphological, physiological, and culture features [14-15]. The current internationally accepted approaches were used for systematization and naming of fungal cultures [16].

\subsection{Fungi prevalence analysis.}

The prevalence of fungi $(\mathrm{P})$ was established using the following formula

$$
\mathrm{P}=(\mathrm{n} / \mathrm{N}) \times 100 \%
$$

where $\mathrm{n}$ is the number of fungi found in our samples (or the number of individual plants affected by fungi in the studied area), and $\mathrm{N}$ is the total amount of samples (or the total number of plants studied in the area).

The following formula was used to quantify the fungi in the soil samples from studied biocenoses:

$$
\mathrm{N}(\mathrm{CFU} / \mathrm{g})=\frac{a \cdot b \cdot c}{d}
$$

where $\mathrm{N}$ is the number of fungi (in $\mathrm{CFU}$ ) per 1 gram of soil, a is the number of colonies in Petri dishes, $\mathrm{b}$ is the dilution factor, $\mathrm{c}$ is the number of drops in $1 \mathrm{ml}$ of suspension, and $\mathrm{d}$ is the amount of soil taken for analysis (in grams).

\subsection{Phytotoxicity analysis.}

The phytotoxicity analysis of isolated fungi was determined, as follows: the fungi were cultivated in liquid Czapek medium (glucose - $14.0 \mathrm{~g} / \mathrm{l}, \mathrm{CaCO} 3-0.7 \mathrm{~g} / \mathrm{l}, \mathrm{KHO} 3$ - $0.7 \mathrm{~g} / \mathrm{l}$, $\mathrm{MgSO} 4-0.35 \mathrm{~g} / \mathrm{l}, \mathrm{K} 2 \mathrm{HPO} 4-0.35 \mathrm{~g} / \mathrm{l}, \mathrm{FeSO} 4$ - trace amounts) for 5 days upon inoculation at $26-28^{\circ} \mathrm{C}$. Then, the produced fungal biomass was removed from the culture medium, which was further used to treat the pea seeds. The phytotoxic activity was determined by the viability (germination ability) of treated seeds expressed as the $\%$ of the negative control mock-treated with an empty Czapek medium.

The proportion of phytotoxigenic fungi among all studied fungal species was determined by analyzing their phytotoxicity activities, and, sometimes, according to the literature data. The effects of temperature, humidity, and other environmental factors on phytotoxigenicity of fungi were analyzed by the accepted methods published elsewhere [11, 17-19].

\subsection{Statistical analysis.}

All experiments were performed in 4 repeats, and the acquired data were statistically analyzed. The following formula was used $S_{m} / M=P \leq 0,05$, where $M$ is the mean indicator of repeats, $S_{x}$ - is the mean square deviation, and P is Student`s criterion [20]. 


\section{Results and Discussion}

\subsection{Identification of fungal species derived from different biotopes.}

We analyzed as much as 2500 soil, water, and plant samples from ecologically different regions of Azerbaijan and isolated 500 pure fungal cultures. The identification of these cultures shows that they represent 130 fungal species. The members of Aspergillus and Pencillium genera are found to prevail in the mycobiota, with 11 and 17 representative species identified, respectively. The results demonstrate that 76 species show phytotoxic activity (inhibition of seed germination), of which 19 species are classified as strongly (> $50 \%$ phytotoxic activity), 32, as an intermediary $(10-50 \%)$, and $25(<10 \%)$, as weakly toxic.

The identified fungal species are found to be distinctly distributed across different biotopes (Table 1). Apparently, soil represents the type of biotope where fungi are encountered most frequently, while water is the less colonized biotope. The highest proportion of phytotoxigenic fungi among the identified fungal species is found in plant-derived microbiotas.

Table 1. Prevalence of fungi and the proportion of phytotoxigenic fungal species isolated from different biotopes.

\begin{tabular}{c|c|c|c} 
Type of biotope & Fungal species (total) & Fungal species (phytotoxygenic) & Proportion of phytotoxigenic species $(\%)$ \\
\hline Soil & 105 & 59 & 56,2 \\
\hline Plant & 72 & 49 & 68,1 \\
\hline Water & 43 & 17 & 39,5 \\
\hline Total & 130 & 76 & 58,5
\end{tabular}

\subsection{Soil moisture preference of the identified fungi.}

Our analysis of fungal species in the soils of different moisture reveals that the hydrophilic fungi defined as those species, the zoospores of which are only able to germinate in the environments with $>50 \%$ humidity, are represented by 7 species all belonging to the phylum of Zygomycota (Table 2). As much as more than 1/3 (35.2\%) of the identified fungal species represent the group of mesohydrophiles, i.e., those that spread in the soils with $10-40 \%$ moisture. Finally, more than $1 / 2(55.3 \%)$ of the identified species belong to the group of xerophilic fungi, the growth and spread of which is not prevented by soil dryness (less than $10 \%$ of moisture) (Table 2).

Table 2. Soil moisture preference of fungi isolated in different regions of Azerbaijan.

\begin{tabular}{|c|c|c|}
\hline Ecological groups & Genera (with number of representative species) & $\begin{array}{l}\text { Proportion in total } \\
\text { phytotoxigenic } \\
\text { microbiota, } \%\end{array}$ \\
\hline Hydrophiles & Absidia (1), Mucor (5), Rhysopus(1) & 9,5 \\
\hline Xerophiles & $\begin{array}{c}\text { Aspergillus (5), Fuzarium (3), Pencillium (7), Candida (2), } \\
\text { Alternaria (3), Phoma (1), Puccinia (4), Verticillium (1), Botrytis } \\
\text { (1), Colletotrichum (2), Cladosporium (2), Paecelomyces } \\
\text { (1), Sphaerotheca (1), Phyllosticta (1), Uromyces (2), Sporothrix } \\
\text { (1), Stemphylium (1), Sclerotina (1), Gymnosporangium (1), } \\
\text { Trichothecium (1), Thielaviopsis (1), }\end{array}$ & 55,3 \\
\hline Mesohydrophiles & $\begin{array}{l}\text { Ascochyta (4), Fusarium (4), Septoria (2), Stachybotrys (1), Monilia } \\
\text { (1), Humicola (1), Macrosporium (1), Penicillium (3), Nectria } \\
\text { (1), Trichoderma (3), Aspergillium (2), Phomopsis } \\
\text { (1), Acremonium(1), Verticillium (2) }\end{array}$ & 35,2 \\
\hline
\end{tabular}




\subsection{Thermal preference of the identified fungi.}

An analysis of the thermal preferences of the identified fungal species shows that psychrophilic species are lacking (Table 3). According to the contemporary classification of fungi with regards to the preferred temperature range, the majority of the identified phytotoxigenic species belong to the mesophiles, while a small number of fungi represent the thermotolerant species. No true thermophilic species defined as those, for which the characteristic optimum temperature is above $55^{\circ} \mathrm{C}$, have been found among the identified phytotoxigenic fungi.

Table 3. Thermal preference of the phytotoxigenic fungi isolated in different regions of Azerbaijan.

\begin{tabular}{c|c} 
Thermal preference $($ optimal growth temperature range) & № of species \\
\hline Psychrophiles $\left(<20{ }^{0} \mathrm{C}\right)$ & 0 \\
\hline Mesophiles $\left(26-300^{0} \mathrm{C}\right)$ & 69 \\
\hline Thermotolerant $\left(35-500^{0} \mathrm{C}\right)$ & 7 \\
\hline True thermophiles $\left(>55^{0} \mathrm{C}\right)$ & 0
\end{tabular}

\subsection{Soil acidity preference of the identified fungi.}

The acidity preference of the identified fungal species was analyzed via the cultivation of fungi in the Czapek medium with different $\mathrm{pH}$ and the determination of fungal colonyforming activity (expressed in CFU per gram of soil). Our analysis shows that the $\mathrm{pH}$ range 4.9-6.5 is optimum for the majority of fungi (Fig. 1). However, some of the identified fungi represent the alkaline-tolerant species, such as Aspergillus fumigatus, Lichtheimia corymbifera and Mucor hiemalis, which are capable of growth at $\mathrm{pH} 9$.

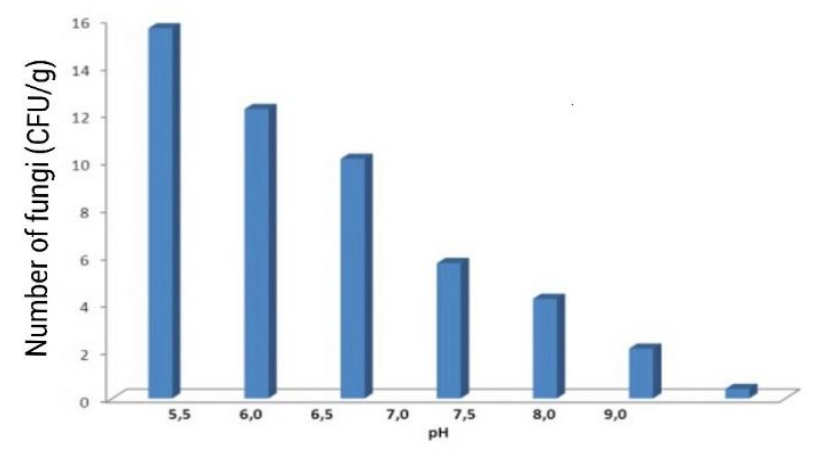

Figure 1. Acidity preference of the identified fungi.

\subsection{Oxygen requirements of the identified fungi.}

Typically, most fungi are aerophiles, but some of the fungal species are aerotolerant anaerobes capable of maintaining their viability under aerophilic conditions. Of interest, we identified some representatives of this group, such as Mucor hiemalis, Lichtheimia corymbifera and Rhizomucor miehei, and only those species were found present in the deep-lying soil samples.

\subsection{Toxigenicity profiles of the identified fungi.}

Noteworthy, a particular group of the identified fungi belongs to the phytotoxigenic ones. The study of the influence of environmental factors on this fungal feature represents a particular interest. To this end, the role of temperature, acidity, and illumination was studied for those fungal species common for the studied regions. 


\subsection{The dependence of fungal phytotoxigenicity on the temperature.}

We first studied the dependence of phytotoxic activity of fungi on the temperature. To this end, we obtained the conditioned growth medium, in which the phytotoxigenic fungi (Aspergillus fumigatus, Aspergillus flavus, Aspergillus niger, Candida albicans, Mucor hiemalis, Paecelomyces variotii, Pencillium chrysogenum, Pencillium notatum) have been cultivated at $20,24,28,32$ or $36^{\circ} \mathrm{C}$, and we determined its phytotoxic activity using the phytotoxicity assay described in the Materials and Methods section.

Our results show that the optimum growth temperature and the temperature of maximum phytotoxic activity do not correspond to most fungal species under study. A $100 \%$ (maximum) phytotoxicity is corresponding to the optimum growth temperature only for the species best growing at $28^{\circ} \mathrm{C}$ (Paecelomyces variotii, Pencillium chrysogenum, Pencillium notatum). Meanwhile, for the species, which grow best at $30^{\circ} \mathrm{C}$ and higher, the highest production of biomass at their optimum temperatures does not correspond to the maximum phytotoxic activity, as can be seen from the data presented in Table 4. Instead, the maximum phytotoxicity temperature of fungal species, which have the growth optimum in the range of $32-35^{\circ} \mathrm{C}$, is $2-3^{\circ} \mathrm{C}$ lower than their optimum growth temperature.

Table 4. The dependence of growth optimum and maximum phytotoxicity temperatures of some phytotoxigenic fungal species.

\begin{tabular}{|c|c|c|c|c|c|c|}
\hline \multirow[t]{2}{*}{ Species } & \multirow{2}{*}{$\begin{array}{l}\text { Optimum growth } \\
\text { temperature }\end{array}$} & \multicolumn{5}{|c|}{ Phytotoxic activity $(\%)$} \\
\hline & & $20{ }^{0} \mathrm{C}$ & $24{ }^{0} \mathrm{C}$ & $28^{0} \mathrm{C}$ & $32{ }^{0} \mathrm{C}$ & $36^{0} \mathrm{C}$ \\
\hline Aspergillus flavus & $32{ }^{0} \mathrm{C}$ & 94 & 97 & 100 & 94 & 90 \\
\hline Aspergillus fumigatus & $32{ }^{0} \mathrm{C}$ & 85 & 96 & 100 & 95 & 87 \\
\hline Aspergillus niger & $30^{0} \mathrm{C}$ & 86 & 97 & 100 & 96 & 76 \\
\hline Candida alpicans & $35{ }^{0} \mathrm{C}$ & 85 & 95 & 100 & 100 & 92 \\
\hline Mucor hiemalis & $32{ }^{0} \mathrm{C}$ & 92 & 97 & 100 & 98 & 95 \\
\hline Pencillium chrysogenum & $28{ }^{0} \mathrm{C}$ & 80 & 93 & 100 & 72 & 15 \\
\hline Pencillum notatum & $28{ }^{0} \mathrm{C}$ & 82 & 94 & 100 & 74 & 14 \\
\hline
\end{tabular}

\subsection{The dependence of fungal phytotoxigenicity on the $\mathrm{pH}$.}

We then studied the relationship between the fungal phytotoxic activity and the acidity, and two important trends have been observed here.

First, the optimum growth $\mathrm{pH}$ and the $\mathrm{pH}$, at which the highest phytotoxic activity was detected, corresponding to each other.

Second, increasing or reducing the acidity from the optimum growth $\mathrm{pH}$ exerts quantitatively different effects on fungal cytotoxicity, which is decreasing more slowly, when the $\mathrm{pH}$ is lower than the optimum one while falling down more rapidly when the $\mathrm{pH}$ is higher than the optimum one. For example, the optimum growth $\mathrm{pH}$ of Mucor hiemalis is 6.0. It is decreasing the $\mathrm{pH}$ to 5.0 results in a $12 \%$ reduction of phytotoxic activity, while it's increasing to 7.0 causes a $25 \%$ reduction of phytotoxic activity (a 2 -fold higher value). A similar trend was observed when calculating the dependence of the specific phytotoxic activity (phytotoxicity per unit of produced biomass). Acidification of growth medium results in a reduction of the specific phytotoxicity, which is 2 -fold lower than that caused by the alkalization. Interestingly, the same holds true of the other fungal species and different plants used for phytotoxicity testing assay (peas, wheat, or barley). Thus, this can be considered a general feature of toxigenic fungi. 


\subsection{The dependence of fungal phytotoxigenicity on the light.}

We then attempted to reveal the effect of light on the phytotoxic activity of toxigenic fungi. We, thus, applied three modes of illumination: first, the fungi were grown in complete darkness (CD), the second involved a 24-hour illumination in the thermostat (CI), and the third mode was based on an alternating circadian illumination simulating the day/night cycle (D/N). In all cases, the experiment on the effects of illumination on fungal phytotoxicity lasted 5 days. Our data show that both complete illumination and complete darkness do not favor the fungal toxigenicity, while the alternating 12 hour/12 hour day/night cycle resulted in the highest toxigenic activity. The phytotoxic activity of fungi cultivated under permanent light conditions was $6-15 \%$ lower than that obtained under alternating day/light conditions, while the full-time illumination caused a 9-20\% reduction of phytotoxicity of different fungal species (Table 5).

Table 5.The effect of illumination on the phytotoxic activity of some identified fungal species.

\begin{tabular}{l|c|c|c}
\multirow{2}{*}{ Species } & \multicolumn{3}{|c}{ Phytotoxic activity under different modes of illumination (\%) } \\
\cline { 2 - 4 } & $\mathrm{CD}$ & $\mathrm{CI}$ & $\mathrm{D} / \mathrm{N}$ \\
\hline Aspergillus flavus & 90 & 94 & 100 \\
\hline A. fumigatus & 80 & 85 & 100 \\
\hline A.niger & 83 & 86 & 100 \\
\hline Albicans fungi & 85 & 89 & 100 \\
\hline Mucor hiemalis & 87 & 92 & 100 \\
\hline Paecelomyces variotii & 90 & 94 & 100 \\
\hline Pencillium chrysogenum & 86 & 89 & 100 \\
\hline Pencillium notatum & 91 & 93 & 100
\end{tabular}

\section{Conclusions}

Fungi inhabit an enormous variety of habitats, and in order to compete with a great number of other living organisms, they acquired the ability to synthesize various [21], including toxic, metabolites as a result of evolution [22]. The dependence of this fungal feature on the environmental factors, which is the study objective in the present work. This study is important for the ecophysiology of fungi, which is attempting to determine the potential limitations of their physiological responses to environmental problems and to study their adaptation to their ecological niches. Being a component of any ecosystem, fungi sustain the constant influence of various biotic and abiotic factors, but the impact of these factors on fungal phytotoxicity requires detailed studies, even within a specific area, such as Azerbaijan territories.

Water is the most important condition of life for any organism, including fungi [23]. However, our data show that very high humidity does not benefit the persistence of true aerophilic fungi. This can be apparently seen in soil biocenoses where the high humidity prevents the efficient aeration and results in a great reduction of fungal species or their complete disappearance.

The ambient temperature also exerts major effects on the growth, spread, and physiological activity of fungi [24]. It also has a great influence on toxin production [25]. Our data show that according to their optimum growth temperature, the fungi studied belong to the group of mesophiles, while the true thermophiles are absent.

We also discovered an intriguing fact that fungi with optimum growth temperature lying in the range of $32-35^{\circ} \mathrm{C}$ do not show maximum phytotoxicity when cultivated at this temperature. Instead, their phytotoxic activity is increased when the incubation temperature is decreased by $2-3^{\circ} \mathrm{C}$ from the optimum one. We believe that this fact can be explained by the notion that toxigenicity is a feature developed by the fungi in the course of their struggle for survival and contributing to their enhanced ability to adapt to their habitats. Most fungi belong 
to the mesophilic organisms with optimum growth temperature lying in the range of $24-30^{\circ} \mathrm{C}$. Thus, the competition of fungal species is the highest within that range. Therefore, the phytotoxigenic activity of all fungi, including those possessing higher optimum growth temperatures, is expected to be highest within this temperature range. Such an explanation needs further corroboration to be conducted in our future research.

Filamentous fungi are known to be tolerant to acidic environments, and the $\mathrm{pH}$ range of 5.0-6.0 is the optimum one for fungal cell growth and metabolism [26]. Our data suggest that mildly acidic environments are optimal for the fungi collected in different regions of Azerbaijan. The distribution of fungi across the biotopes with different soil acidity indicates that the amount of fungi in acidic soils is much higher than that in neutral and mildly alkaline soils. However, some of them found fungal species have the acidity preferences way beyond the $\mathrm{pH}$ range indicated above (and ranging from $\mathrm{pH} \sim 3$ to $\mathrm{pH} \sim 9$ ).

We also report that the amount of humus in the soil is positively affecting the prevalence of fungi in addition to soil acidity. For example, the soils with higher humus content will have a higher prevalence of fungi, than the soils of similar acidity, but containing less humic substances.

Finally, the light does not play such an important role for fungi compared to plants [27]. However, according to the published data, light has a particular effect on the living of fungal species [28], which is also confirmed by our experimental data. We showed that even the modes of illumination affect both fungal growth and their phytotoxigenic activity. The alternating day/night cycle is most favorable for the fungal toxigenicity, while complete darkness or, to a lesser extent, complete illumination results in reduced phytotoxicity.

Our study of ecophysiological features of phytotoxigenic fungi from ecologically different territories of Azerbaijan reveals the functional limits of fungal persistence in ecosystems with regards to several environmental factors (temperature, humidity, acidity, and light). In an established collection of 130 soil-, water-, and plant-derived fungal species, as much as 76 species show phytotoxic activity (inhibition of seed germination), of which 19 species are classified as strongly ( $>50 \%$ phytotoxic activity), 32, as an intermediary (10-50\%), and $25(<10 \%)$, as weakly toxic.

The study of the role of abiotic environmental factors, such as ambient temperature and acidity, oxygen availability, soil moisture, and illumination on the ecophysiological features of the studied toxigenic fungi, reveals that they have different influence on fungal prevalence and phytotoxigenicity, and their effects are exerted in an interaction between the character of the environmental factor and the biological features of fungi. The obtained data indicate that, although some environments are stressful for fungi and may disturb their homeostasis, some fungal species are able to inhabit, grow, and reproduce under such difficult conditions.

\section{Funding}

This research received no external funding.

\section{Acknowledgments}

The authors declare no acknowledgment.

\section{Conflicts of Interest}

The authors declare no conflict of interest. 


\section{References}

1. Agusti-Brisach, C.; Armengol, J. Effects of Temperature, $\mathrm{pH}$ and Water Potential on Mycelial Growth, Sporulation and Chlamydospore Production in Culture of Cylindrocarpon species Associated with Black Foot of Grape vines. Phytopathol. Mediterr.2012, 51, 37-50.

2. Cairns, T.C.; Nai, C.; Meyer, V. How a fungus shapes biotechnology: 100 years of Aspergillus niger research. Fungal BiolBiotechnol. 2018, 5, p. 13.

3. Bakhshaliyeva, K.F.; Cabrayılzadə, S.M.; İslamova, Z.B.; Namazov, N.R.; Hasanova A.R. The General Characteristic of Anamorphic Fungi Spread In Azerbaijan. Int J Recent Technol Eng.2019, 8 2208-2210, https://doi.org/10.35940/ijrte.c4591.098319.

4. Halme, P.; Heilmann-Clausen J.; Rama T.; Kosonen T.; Kunttu R. Monitoring fungal biodiversity - towards an integrated approach. Fungal Ecol. 2012, 5, 750-758, http://dx.doi.org/10.1016/j.funeco.2012.05.005.

5. Chen, A.J.; Jiao, X.L.; Hu, Y.J.; Lu, X.H.; Gao, W.W. Mycobiota and mycotoxins in traditional medicinal seeds from China. Toxins, 2015, 7, 3858-3875, https://dx.doi.org/10.3390\%2Ftoxins7103858.

6. Country Study on Biodiversity of Azerbaijan Republic. Fourth National Report to Convention of Biological Diversity. Available online: https://www.cbd.int/doc/world/az/az-nr-04-en.pdf (accessed on 11 January 2020)

7. David, L.H.; Tom, W.M.; Scott, A.R. Fungal nomenclature evolving: changes adopted by the 19th International Botanical Congress in Shenzhen 2017, and procedures for the Fungal Nomenclature Session at the 11th International Mycological Congress in Puerto Rico 2018. IMA Fungus2017, 8, 211-218, https://doi.org/10.5598/imafungus.2017.08.02.01.

8. Dubey, M.K.; Aamir, M.; Kaushik, M.S. PR Toxin - Biosynthesis, Genetic Regulation, Toxicological Potential, Prevention and Control Measures: Overview and Challenges. Front Pharmacol. 2018,9, 288, https://doi.org/10.3389/fphar.2018.00288.

9. Ahmad, B.; Ashiq, S.; Hussain, A.; Bashir, S.; Hussain M. Evaluation of mycotoxins, mycobiota, and toxigenic fungi in selected medicinal plants of Khyber Pakhtunkhwa, Pakistan. Fungal Biol. 2014,118, 776-784, https://doi.org/10.1016/j.funbio.2014.06.002.

10. Fuller, K.K.; Dunlap, J.C.; Loros, J.J. Chapter One - Fungal Light Sensing at the Bench and Beyond. Adv Genet 2016, 96, 1-51, https://doi.org/10.1016/bs.adgen.2016.08.002.

11. Gregory, M.M.; Gerald, F.B.; Mercedes, S.F. Biodiversity of Fungi: Inventory and Monitoring Methods. Burlington, Academic Press, 2004.

12. Handbook of Mycological Methods. Available online: http://www.fao.org/fileadmin/user_upload/agns/pdf/coffee/Annex-F.2.pdf(accessed on 11 January 2020)

13. Hyde, K.D.; Xu, J.; Rapior, S. The amazing potential of fungi: 50 ways we can exploit fungi industrially. Fungal Divers. 2019, 97, 1,https://doi.org/10.1007/s13225-019-00430-9.

14. Kirk, P.M.; Cannon, P.F.; Minter, D.W.; Stalpers, J.A. Dictionary of the fungi. $10^{\text {th }}$ ed.. Wallingford, CABI publishing, 2008.

15. Kowalska, A.; Walkiewicz, K.; Koziel, P.; Muc-Wierzgoń, M. Aflatoxins: characteristics and impact on human health. Postepy Hig. Med. Dosw. 2017, 71, 315-327, https://doi.org/10.5604/01.3001.0010.3816.

16. Lakin, G.F. Biometrics. Moscow, Higher school, 1990; pp. 352

17. Mazurkiewicz-Zapałowicz, K.; Silicki, A.; Gregorczyk, A. Effects of some abiotic factors on the occurrence of aquatic mycobiota in lakes of the Drawa National Park. Oceanol Hydrobiol St 2012, 41, 8-16, https://doi.org/10.2478/s13545-012-0034-y.

18. Moore, M.L.; Six, D.L. Effects of Temperature on Growth, Sporulation, and Competition of Mountain Pine Beetle Fungal Symbionts. Microb Ecol. 2015, 70, 336-347, https://doi.org/10.1007/s00248-015-0593-8.

19. Rahi, D.K.; Malik, D. Diversity of Mushrooms and Their Metabolites of Nutraceutical and Therapeutic Significance. J. Mycol. 2016, 18, https://doi.org/10.1155/2016/7654123.

20. Lange, L. The importance of fungi and mycology for addressing major global challenges. IMA Fungus 2014, 5, 463-471, https://doi.org/10.5598/imafungus.2014.05.02.10.

21. Csutak, O., Stoica, I., Vassu, T. Molecular identification and antimicrobial activity of two new Kluyveromyces lodderae and Saccharomyces cerevisiae strains. Biointerface Research in Applied Chemistry, 2014, 4, 873878.

22. Satton, D.; Fothergill, A.; Rinaldi, M.Determinant of pathogenic and conditionally pathogenic fungi. Moscow, World, 2001.

23. Siciliano, S.D.; Palmer, A.S.; Winsley, T. Soil fertility is associated with fungal and bacterial richness, whereas $\mathrm{pH}$ is associated with community composition in polar soil microbial communities. Soil Biol. Biochem. 2014, 78, 10-20, https://doi.org/10.1016/j.soilbio.2014.07.005.

24. Singh, A. Optimal Physical Parameters for Growth of Trichoderma Species at Varying pH, Temperature and Agitation. VirolMycol.2014,3, https://doi.org/10.4172/2161-0517.1000127.

25. Smilanick, J.L.; Mansour, M.F. Influence of temperature and humidity on survival of Penicilliumdigitatum and Geotrichumcitri-aurantii. Plant Dis. 2007, 91, 990-996, https://doi.org/10.1094/PDIS-91-8-0990.

26. Tang, W.; Kuehn, T.H.; Simcik, M.F. Effects of Temperature, Humidity and Air Flow on Fungal Growth Rate on Loaded Ventilation Filters. J Occup Environ Hyg 2015,12, 525-537, https://doi.org/10.1080/15459624.2015.1019076. 
27. Sandoval-Contreras, T.; Villarruel-López, A.; Sierra-Beltrán, A.P.; Torres-Vitela, R.; Ascencio F. Effect of $\mathrm{pH}$ and temperature in production of mycotoxins and antibiotics by phytopathogenic moulds for Persian lime (Citrus latifolia T.) in a complex lime pericarp-base medium. Emir J Food Agr 2017, 29, 751-759, https://doi.org/10.9755/ejfa.2017.v29.i10.1293.

28. Zeidan, R.; Ul-Hassan, Z.; Al-Thani, R.; Balmas, V.; Jaoua, S. Application of Low-Fermenting Yeast Lachancea thermotolerans for the Control of Toxigenic Fungi Aspergillus parasiticus, Penicillium verrucosum and Fusarium graminearum and Their Mycotoxins. Toxins 2018, 10, 242 , https://doi.org/10.3390/toxins10060242. 